\title{
Linguistic Agency Assignment in The Star Online Headlines on COVID-19
}

\author{
FAKHIRA JAFRI \\ Kulliyyah of Islamic Revealed Knowledge \& Human Sciences \\ International Islamic University Malaysia, Malaysia \\ ADLINA ARIFFIN \\ Kulliyyah of Islamic Revealed Knowledge \& Human Sciences \\ International Islamic University Malaysia, Malaysia \\ adlina@iium.edu.my
}

\begin{abstract}
The media coverage on the COVID-19 pandemic has caused emotional distress among people. This calls for a close scrutiny of health-related information on COVID-19 disseminated via news headlines. It is essential to determine which context - risk, prevention, or treatment - needs to be emphasised in covering news related to a pandemic and whether such reporting leads to public health scare or health consciousness. This paper discusses a study which investigated this issue by adopting Linguistic Agency Assignment as the framework in analysing COVID-19 related news headlines of a Malaysian mainstream news outlet, The Star Online. Extended Parallel Process Model (EPPM) was used to examine whether the writings induced fear or created awareness among the public. Findings of the thematic and textual analysis of a corpus of news headlines revealed that the Malaysian mainstream newspaper often disseminated prevention-themed messages related to COVID-19, used more human agency language, and induced fear in the audience, while at the same time, delivered a high level of COVID-19 awareness to readers.
\end{abstract}

Keywords: linguistic agency assignment; linguistic strategies; online news headlines; Extended Parallel Process Model; COVID-19

\section{INTRODUCTION}

The role of news media in disseminating health-related information is most prominent, especially in facing the current COVID-19 pandemic. Since the emergence of this health threat in late January 2020, related issues such as symptoms, preventive measures, restriction orders, and vaccination have been covered by the media platform in congruent with the development of the pandemic. According to Berry et al. (2007), generally, in the dissemination of information on diseases, the media focus on risks rather than prevention and treatment. This notion is further supported by Sandman (1994, p.254) that in the media, "alarming content about risk is more common than reassuring content or intermediate content...". Thus, the alarmist nature of news coverage can increase one's anxiety level (Pokharel, 2015). This unpleasant feeling can be transferred virtually to other people when "the reader concludes an article just by reading the headline... and then sharing it on their social media" (Kertanegara, 2018, p. 58).

In this respect, 'prevention' refers to the preventive measures implemented globally to contain the spread of the Coronavirus which among others are sanitization, mask wearing and restricted movement control orders (Venes, 2017). Risk, on the other hand, is the reason for the preventive measures to be executed as it reflects the potential for the occurrence of threatening consequences, while treatment relates to the medical procedures carried out to ameliorate diseases (Venes, 2017).

Headlines are the most essential elements of every news writing. Conboy (2007) proposed that headlines serve three significant functions: providing brief summaries of the 
main ideas of news reports, providing initial indicators of the contents and styles of the news values, and attracting readers' attention. A study from the Media Insights Project revealed that 6 out of 10 people only read the headlines of articles (Cillizza, 2014). According to Steuter and Wills (2009), "it is worth paying attention to news headlines because they are, for a large part of the population, a main source of information; many people glean their knowledge from scanning headlines rather than reading the whole articles" (p.74). Hence, an investigation on the news headlines covering the pandemic is most salient as most people nowadays tend to rely on information stated in news headlines only.

As the news coverage on COVID-19 spread, panic dissipates. People were stockpiling necessities such as food, hand sanitizers, masks, and soaps, emptying the stores' shelves. There can be no doubt that the consumption of news is associated with anxiety. According to Pokharel (2015), diseases and global epidemics pose a high level of threat to the world and often become objects of moral panics. It can trigger one's health anxiety and engage in dysfunctional behaviours such as stockpiling essential needs and demanding irrational medical needs (Vigo et al., 2020). These behaviours are often influenced by news reports covering illnesses even before the outbreak truly occur (Bada et al., 2019; Vigo et al., 2020). Of more concern, these behaviours can be stimulated by reading only the news headlines. According to Faheem Aslam et.al., (2020), news headlines have the potential to evoke readers' fear, anxiety and other negative sentiments and emotions especially when disseminating information of epidemic outbreaks, including COVID-19 outbreak. It can be implied that the language use in the headlines play a crucial role in governing readers' behaviours.

The scenarios above accentuate the power of the media in provoking certain reactions and behavioral manifestations among the masses. Therefore, a look into how news headlines affect the public's reactions is crucial to maintain a controlled surrounding and to keep the public safe from the deadly virus. Hence, the current research aimed to examine the linguistic agency assignments in news discourse in the headlines and determine whether there is a balance in disseminating health-related messages in terms of prevention, risk and treatment published by The Star Online which is the most frequently read online English language newspaper in Malaysia ("Malaysia's 2019 Media Consumption Report", 2019).

\section{EFFECTS OF LINGUISTIC AGENCY ASSIGNMENT IN DISSEMINATING HEALTH MESSAGES}

According to Jackendoff (1972, as cited in Zhang \& McGlone, 2018), the notion of 'agency' is to exhibit who is responsible for an event to happen, it can either be a person or an object. Seale (2004) opined that health scares are more likely to be evoked among the public when humans are portrayed as villains in any form of narrative where they are made to be responsible for health damages. When the 'villain' is represented in a text as a social threat, health scare can take the form of a moral panic. By referring to this notion, it is important to find the 'villain' or the actor to reduce the elevation of anxiety level among the public, one of the ways is through linguistic agency assignment.

Bell et al. (2014) investigated how linguistic agency assignment affected perceptions on severity and health threat, response efficacy, fear arousal and intentions to adopt the recommendations of health protection from bacteria of Human Papillomavirus (HPV) in educational materials specifically flyers. The results revealed that assignment of agency to bacteria can affect people's perceptions of the threat, i.e. virus. They added that participants have a higher level of susceptibility and severity when bacteria were assigned as the agency. However, the participants' response efficacy, self-efficacy and fear arousal were not affected when bacteria were the agent. For the intention to adhere to healthcare recommendations, the participants reported to have higher intentions of adopting it. This is because the discussion of 
the bacteria has been a part of the public dialogue and has been going on for many years in contrast to a discussion on a pandemic, for instance, a sudden outbreak of H1N1.

Zhang and McGlone (2018) examined the effects of linguistic agency assignment on Human Papillomavirus (HPV) prevention advocacy in Chinese public health education materials and whether the functions of linguistic agency assignment were similar in the English language context. They found that the effects of linguistic agency used in English language context from previous studies functioned similarly within the Chinese language context. They also found that the participants tended to have a higher level of personal susceptibility when linguistic agency was assigned to the vaccine than human. For example, the statement "All children need to come under the protection of an HPV vaccine" will make the respondents feel more at risk of HPV instead of "All children need to protect themselves by getting an HPV vaccination".

In another study, Chen et al. (2015) investigated persuasive effects of linguistic agency assignments and point of view in health messages regarding colon cancer. It should be noted that this study focused on narrative writing rather than expository writing. They intended to examine three things which were the effects of linguistic agency assignment in narrative messages to 'cancer' or 'human', the impact of temporal agency assignments to death and dying patient and whether the effects of agentic language in a narrative are shaped by the Point of View (POV) in which linguistic assignment are embedded i.e., from first person singular or third person singular. Based on the questionnaires, they found that the participants had higher levels of susceptibility when assigning the agency to 'humans' rather than to 'cancer'. For instance, the sentence "This year, more than 100,000 people will develop colon cancer. Half of us will die from it" elevated participants' level of susceptibility compared to when the agency was assigned to 'cancer' as in 'This year, more than 100,000 people will be struck by colon cancer. Half of us will be killed by it" (Chen et al., 2015, p.981). Furthermore, in terms of fear, death-approach language led to greater fear e.g. "Death often comes quickly to us" compared to human-approached language e.g. "We often go quickly to our deaths" (Chen et al., 2015, p.983). In terms of persuasiveness, human-approached language appeared to be more persuasive than death-approach language when first person POV narrative was applied, for example, "I move toward death" (Chen et al., 2015, p.984).

Previous studies have presented the effects of linguistic agency assignment in disseminating information on various diseases via health-related materials such as public educational materials. Drawing on these findings, the current study investigated whether the use of linguistic agency assignment in news headlines promoted fear or awareness among the public, focusing on the coverage of COVID-19 outbreak in a Malaysian online newspaper.

PREVENTION, RISK AND TREATMENT OF COVID-19

This section is constructed to get an insight of the concepts of 'prevention', 'risk' and 'treatment' of Covid 19 to build a common understanding of the terms used in the study. First, the term 'prevention' in the medical dictionary refers to "the anticipation of harm, disease or injury and the measures taken to block their effects" (Venes, 2017, p.1919). The National Institute of Public Health \& Environmental Protection (PHEP) (as cited in Maas, 2016) divided prevention into three types which are disease prevention, health promotion and health protection. The meaning for each type of prevention is explained in Table 1 below. 
TABLE 1. Types of Prevention (PHEP cited in Maas, 2016)

\begin{tabular}{ll}
\hline Prevention Type & Meaning \\
\hline Disease Prevention & Measures that are designed to prevent a particular disease even at its early detection stage. \\
& Measures include screening, vaccinations and preventive medication. \\
Health Promotion & Promotes and maintains a healthy lifestyle, social and environment. \\
Health Protection & Protects the people from health-threatening factors. \\
\hline
\end{tabular}

Based on the above descriptions, it could be agreed that measures such as lockdown, travel ban, border control, social distancing, social isolation and contact tracing are some examples of prevention implemented by governments around the world to contain the Coronavirus and protect the people.

Next, the term 'treatment' is defined as "any specific procedure used for the cure or amelioration of a disease or pathological condition" (Venes, 2017, p.2400). To date, there is no specific treatment or cure for COVID-19 except for the vaccination efforts that are being implemented globally. However, during the initial stage of the pandemic the news media circulated several claims made by both experts and non-experts that Coronavirus could possibly be cured through, for instance, stem cell therapy ("Stem cell therapy", 2020), herbs ("Indonesia president Jokowi", 2020), Chinese traditional medicine ("China using traditional", 2020) and others.

The term 'risk' in the medical dictionary refers to "the probability that a loss or something dangerous or harmful will occur" (Venes, 2017, p.2071). Douglas (1992) believed that risk is not only limited to the probability of an occasion but also the plausible degree of its outcome as well as the subjective meaning attached to it. Due to the obscurity of COVID-19, the public are well informed about the risks. In order to mitigate the risk of transmitting the virus to others, preventative measures need to be adhered to.

Although there are various definitions pertaining to prevention, risk and treatment proposed by scholars, the above-mentioned concepts were selected in accordance to the focus of the present study. The concepts were presented to facilitate the researcher in conducting the thematic analysis of the news headlines as a guidance to generate codes as well as to classify them under the corresponding themes.

\section{CONCEPTUAL FRAMEWORK}

\section{LINGUISTIC AGENCY ASSIGNMENT}

There are varieties of linguistic strategies that writers can choose from to describe an event and one of them is linguistic agency assignment. It is often used by health professionals as a method to affect audiences' perceptions on a particular threat, specifically a disease (Bell et al., 2014). McGlone et al., (2013, p.741) defined agency assignment as "the ascription of action or change to one or more event-related entities". McGlone et al. added that the choice of assignment may influence people's perception of threat and make them think of the ways to safeguard themselves from it. For example, when people are told they could 'contract' the virus (e.g. "six million Americans contract genital HPV each year"), this is due to their own impending actions, however, when a particular virus informed that it could 'infect' the people (e.g. "genital HPV infects six million Americans each year", it shifts the responsibility onto the virus instead which indirectly turns the virus into a villain (Bell et al., 2014). It is believed that assigning agency to the virus will heighten one's perceived severity and perceived susceptibility to the threat rather than assigning agency to human (McGlone et al., 2013). Thus, the notion of agency assignment indicates who or what is responsible for the action which the agent is determined by the relationship to the action expressed by the verb. 


\section{WITTE’S (1992) EXTENDED PARALLEL PROCESS MODEL (EPPM)}

EPPM is a health risk message theory usually used by health professionals to create health messages and motivate health-related behaviour among the audience (Thompson et al., 2011). The changes in readers' behaviours, attitudes as well as intentions are based on the effects of threat severity, personal susceptibility, self-efficacy and response efficacy. These four elements are deemed to be effective in designing health messages. As suggested by EPPM, readers will evaluate the severity and susceptibility of a particular threat when confronting a health risk (Witte et al., 1998). If they believe that they are vulnerable to a serious threat, they will then evaluate the effectiveness of the writer's recommendations (response efficacy) and their ability to enact the given recommendations (self-efficacy) (Zhang and McGlone, 2018).

The higher the level of perceived threat and perceived efficacy the more likely for individuals to engage in danger control in which they will follow the suggested recommendations (Thompson et al., 2011). On the other hand, if the perceived threat is high and perceived efficacy is low, the readers are likely to engage in fear control in which they will do things that will reduce only the fear by avoiding or denying the writer's recommendations (Thompson et al., 2011). This is because they feel that they are unable to protect themselves from the threat. Witte (1992) mentioned that fear is evoked because the perceived threat becomes more intensified by the inability of individuals to prevent the threat. He added that when fear control is established, "individuals respond to their fear, not to the danger" (p.226). For example, an outgoing person may convince herself or himself that Coronavirus is spread because of not wearing a mask only, and not because of close contact or touching people or things recklessly (as the virus can be transmitted via airborne particles and droplets). If fear is not aroused (no threat perceived), thus, there will be no response (either danger control or fear control) from readers. An illustration of the EPPM process is presented in Figure 1 below.

In order to find whether the dissemination of health messages using linguistic agency assignment provides awareness or creates fear to the public, the current study would determine danger control as self-awareness and fear control as health scare or fear to the public.

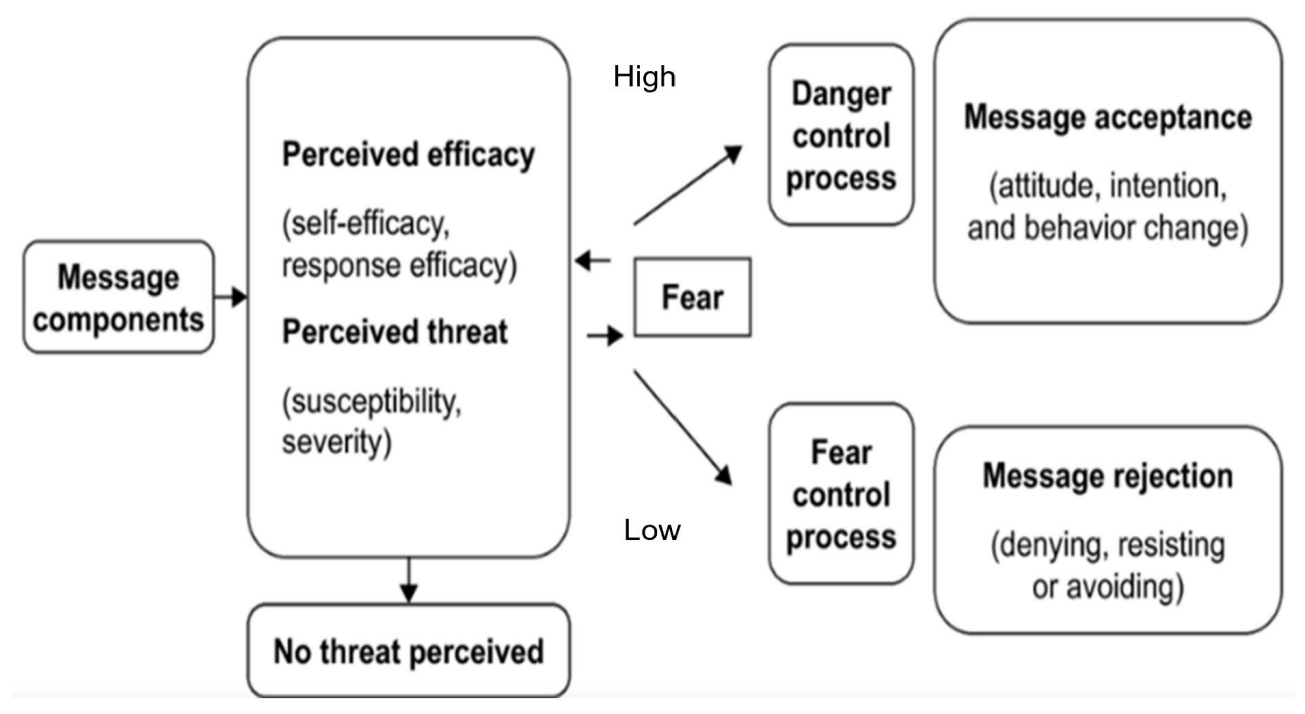

FIGURE 1. Conceptual framework of Witte's EPPM (as cited in Zonouzy et al., 2019) 


\section{METHODOLOGY}

The present study employed a mixed-method approach where it involved descriptive qualitative method of textual analysis and thematic analysis, and quantitative method. The Star was chosen for this study because it is among the most trusted Malaysian sources of news ("Reuters report", 2018). The selected news headlines covered the events related to COVID19 worldwide which were obtained from the 'News' section of The Star Online during March 2020. Bell et al.'s (2014) EPPM questionnaire was utilised to investigate the effects of the news headlines on the masses. The current study involved a total of 20 participants aged 19 to 62 years old which included university students, working and non-working individuals. They were divided into two groups; the first group was given virus agency as stimuli, the second group was given human agency as stimuli. Modifications were made to the questionnaire to fit the focus of the study. Apart from the four existing variables (severity, susceptibility, selfefficacy and self-response), two additional variables were added which were fear arousal and behavioral intentions. Responses to the variables were made on 5 Likert-type scales ranging from 1 (strongly disagree) to 5 (strongly agree).

\section{DATA ANALYSIS}

Braun and Clarke's (2006) thematic analysis (refer to Table 2) was adopted to distribute the headlines into their respective themes which were Prevention, Risk and Treatment. They developed a six-phase guide to find the themes for qualitative data.

TABLE 2. Braun \& Clarke's six-phase thematic analysis framework.

\begin{tabular}{ll}
\hline \multicolumn{1}{c}{ Steps } & \multicolumn{1}{c}{ Descriptions } \\
\hline Step 1: Become familiar with the data & $\begin{array}{l}\text { Read the data thoroughly to get familiar with it and jot down important } \\
\text { notes. }\end{array}$ \\
Step 2: Generate initial codes & $\begin{array}{l}\text { Identify a particular feature. It can be done manually or using a } \\
\text { software programme. }\end{array}$ \\
& $\begin{array}{l}\text { Sort the codes into themes. } \\
\text { Step 3: Search for themes }\end{array}$ \\
Ensure the data fits with the themes. \\
Step 5: Define themes & $\begin{array}{l}\text { Refine the themes by identifying the 'essence' of what the themes are } \\
\text { about. }\end{array}$ \\
Step 6: Write-up & Write the analysis of the data. \\
\hline
\end{tabular}

\section{FINDINGS AND DISCUSSION}

\section{COMMON HEALTH-RELATED THEMES USED IN THE NEWS HEADLINES}

From the thematic analysis, 733 news headlines (from a total of 3000) were identified and classified under the three themes. The content of the remaining news headlines were either vague (e.g. "Preparing for a pandemic") or not related to Prevention, Risk and Treatment (e.g. "Johor Amanah chief appointed state opposition leader"). Codes for Prevention encompassed border control, social quarantine, social distancing, protective kit, sanitisation, medical equipment, diet, self-care, lockdown, and vaccine development. Codes for Treatment were traditional medicine, therapy, blood plasma and drugs. Codes for Risk included deathrisk of infected people, infection-risk of certain groups of people and transmission risk of invisible threat. The proportion of the codes to the respective themes is presented in Table 3. 
TABLE 3. Distribution of news headlines based on Prevention, Risk and Treatment

\begin{tabular}{cccc}
\hline THEMES & Prevention & Risk & Treatment \\
\hline TOTAL & 495 & 226 & 13 \\
\hline
\end{tabular}

Health topics related to COVID-19 were mostly discussed in terms of Prevention (495) followed by Risk (226) and Treatment (13). The news headlines on COVID-19 which related to prevention measures to curb the virus were border control (e.g. "Colombia closes border with Venezuela over coronavirus"), lockdown (e.g. "We are at war': France imposes lockdown to combat virus"), social distancing (e.g. "Keep your distance in Singapore”), among others. One of the most probable reasons for the emphasis on Prevention in March 2020 was that since the cure has yet to be found, the main aim of the news was to disseminate massive information on several measures to reduce or slow down the spread of the virus infection. Also, in order to persuade the public to adhere to the preventative measures, the news headlines focusing on Risk were utilised to catch the attention of the public on the outcome of getting infected, such as death, for example "Another Wuhan doctor treating Covid-19 patients dies from infection". The least discussed issue is on Treatment since there was still no available treatment in March 2020 .

\section{TYPE OF THREAT AGENCIES I.E. VIRUS ASSIGNMENT OR HUMAN ASSIGNMENT THAT IS MOSTLY USED IN THE NEWS HEADLINES}

As stated before, the role of agency assignment is to know who or what is responsible for an event or action. The distribution of virus agency and human agency in the news headlines disseminating health-related messages on COVID-19 can be seen in Table 4.

TABLE 4. The distribution of virus agency and human agency in news headlines

\begin{tabular}{lcc}
\hline Themes & $\begin{array}{c}\text { Virus Agency } \\
\text { Assignment }\end{array}$ & $\begin{array}{c}\text { Human Agency } \\
\text { Assignment }\end{array}$ \\
\hline Prevention & 4 & 0 \\
Risk & 11 & 21 \\
Treatment & 0 & 0 \\
Total & $\mathbf{1 5}$ & $\mathbf{2 1}$ \\
\hline
\end{tabular}

It was found that the highest type of linguistic agency appeared in the news headlines was human agency assignment with 21 occurrences followed by virus agency assignment, 15 occurrences. There was no threat agency assignment of virus or human used in Treatment. This is understandably so since in March 2020 the pandemic was still at its initial stage, hence, treatment was still in its infancy. It could be alluded that journalists tend to employ human agency assignment in news headlines when disseminating risk-related issues on COVID-19. For instance, "Covid-19: 307,200 people infected and more than 13,000 dead" and "Nine doctors die from coronavirus in Philippines". This might be due to the fact that the journalists wanted to enlighten the readers that they could become the potential cause for an event to happen as in this case, virus transmission. The journalists established the role or responsibility of humans when discussing risk with the hope that they would adhere to the prescribed measures. Zhang and McGlone (2018) believed that the usage of agentic language can enhance persuasive effect in a message to persuade readers to do something specifically in terms of protecting themselves from any threat. The responsibility of the human agent was determined by the relationship to the action expressed by the verb "spread", "die(s)", "infected/infects", "may be", "becomes" and others.

A similar trend is noted when Coronavirus was assigned as the responsible agent. Virus agency assignment transforms a virus into a villain, making people perceive it as a threat. In this news headline, "Virus kills three more in Thailand", it infers that the virus is responsible 
for killing the victims, due to the action or verb 'kill' assigned to the virus. Moreover, it posits that the virus has the ability to threaten humans. This might be one of the writers' strategies to inform the public that Coronavirus is a serious threat and the probability or risk of someone getting 'killed' by it is high. It is indubitable that news media do play a crucial part within the social construction of risk by having the authority to report an event in a certain way which can influence people's perceptions of risks (Pokharel, 2015).

\section{EFFECTS OF THE DISSEMINATION OF HEALTH MESSAGES AMONG THE PUBLIC}

A questionnaire was developed and distributed to the respondents to examine whether linguistic agency assignment (virus as agency versus human as agency) poses health scare or create awareness. The respondents were divided into two groups with $10 \mathrm{in}$ each group. The first group was given human agency language as the stimuli while the second group was given virus agency language (refer to Table 5). The stimulus consisted of both Risk and Prevention messages since these were the 2 main themes identified in the news headlines. No Treatment messages were included due to the absence of linguistic agency assignment (refer to Table 4).

TABLE 5. Sample of stimulus for virus agency assignment and human agency assignment

\begin{tabular}{|c|c|}
\hline Human Agency Assignment & Virus Agency Assignment \\
\hline $\begin{array}{l}\text { 1. "Covid-19: Over } 87,000 \text { infected globally, nearly } 3,000 \\
\text { dead" } \\
\text { 2. "Covid-19: More than } 89,000 \text { infected, over } 3,000 \text { dead" } \\
\text { 3. "Another Wuhan doctor treating Covid-19 patients dies } \\
\text { from infection" } \\
\text { 4. "My 'Ayah' passed away from Covid-19, says daughter in } \\
\text { heart-rending tweets" } \\
\text { 5. "People with blood type A may be more vulnerable to } \\
\text { coronavirus, China study finds" }\end{array}$ & $\begin{array}{l}\text { 1. "Iran's military on alert as virus kills } 77 \text {, sickens leaders" } \\
\text { 2. "Coronavirus spreads fear, isolation, death to elderly } \\
\text { worldwide" } \\
\text { 3. "Virus kills three more in Thailand" } \\
\text { 4. "A daughter learns in voicemails that coronavirus has killed } \\
\text { her mother" } \\
\text { 5. "WHO: Covid-19 pandemic has killed } 30,105 \text { people } \\
\text { worldwide" }\end{array}$ \\
\hline
\end{tabular}

HUMAN AGENCY LANGUAGE AS STIMULI

The percentages of perceived threat and perceived efficacy of participants who received human agency language as stimuli is presented in Table 6.

TABLE 6. Percentages of participants' perceived threat and perceived efficacy

\begin{tabular}{llcccccc}
\hline & Item & S.D & D & N & A & S.A & \% \\
\hline Perceived Threat & Severity & 0 & 0 & 0 & 6 & 4 & $\mathbf{5 0 . 3 \%}$ \\
& Susceptibility & 0 & 1 & 2 & 5 & 2 & \\
\hline Perceived Efficacy & Self-efficacy & 0 & 0 & 0 & 9 & 1 & $\mathbf{4 9 . 7 \%}$ \\
& Response Efficacy & 0 & 0 & 2 & 6 & 2 & \\
\hline \multicolumn{2}{l}{ Note: Numbers for Strongly Disagree (S.D) $=$ 1, Disagree (D) $=2$, Neutral (N) $=3$, Agree (A) $=4$, Strongly Agree (S.A) $=5$}
\end{tabular}

Based on Table 6 , the percentage of perceived threat was $50.3 \%$, which is slightly higher compared to the percentage of perceived efficacy which was $49.7 \%$. Most of the respondents perceived the presented threat as severe where 6 respondents rated 'Agree' whereas 4 respondents rated 'Strongly Agree'. Nevertheless, most of the respondents believed that they were able to protect themselves from the threat or virus, where 9 of them rated 'Agree' and 1 of them rated 'Strongly Agree' for self-efficacy. Table 7 presents the mean of each item under perceived threat and perceived efficacy. 
3L: Language, Linguistics, Literature ${ }^{\circledR}$ The Southeast Asian Journal of English Language Studies Vol 27(4), December 2021 http://doi.org/10.17576/3L-2021-2704-03

TABLE 7. Summary of Mean for perceived threat and perceived efficacy

\begin{tabular}{lllcc}
\hline & Item & Mean & Scale Total & Scale Average \\
\hline Perceived Threat & Severity & 4.4 & & \\
& Susceptibility & 3.8 & 8.2 & $\mathbf{4 . 1}$ \\
\hline Perceived Efficacy & Self-efficacy & 4.1 & 8.1 & $\mathbf{4 . 0 5}$ \\
& Response Efficacy & 4 & & \\
\hline
\end{tabular}

The results from the calculation of the mean scores of the theoretical variables as shown in Table 7 revealed that perceived severity of threat was at the highest level with an average score of 4.4. Self-efficacy was the second highest with a mean of 4.1 followed by response efficacy 4 . Nonetheless, the lowest level was perceived susceptibility of threat with a mean of 3.8. All participants recognised Coronavirus as a severe threat but some of them felt that they were not susceptible to getting infected by it. This could be due to many factors such as age, employment and health conditions. For instance, elderly people and those with medical conditions are said to have a higher risk of getting infected than others. Also, the degree of exposure depends on the participants' occupations where some of the jobs do require them to work relatively close to other people while some do not.

As stated by Witte (1992), if the scores for both perceived threat and perceived efficacy are high, the danger control will be initiated. In this case, although perceived threat was slightly higher than perceived efficacy, the scale average for both items which were 4.1 and 4.05 respectively, were still in the range of 'Agree', indicating that most of the respondents agreed that Coronavirus is indeed dangerous, which indirectly stimulated an action to ward off the virus. Hence, it could be deduced that the participants were in a danger control process indicating that they were going towards protection motivation. Therefore, the assignment of agency to human induced fear but at the same time created awareness among the respondents as they were aware that they have to be cautious in everything they do and protect themselves from the threat.

\section{VIRUS AGENCY LANGUAGE AS STIMULI}

The percentages of perceived threat and perceived efficacy of participants who received virus agency language as stimuli are presented in Table 8 .

TABLE 8. Percentages of participants' perceived threat and perceived efficacy

\begin{tabular}{|c|c|c|c|c|c|c|c|}
\hline & Item & S.D & D & $\mathbf{N}$ & $\mathbf{A}$ & S.A & $\%$ \\
\hline \multirow[t]{2}{*}{ Perceived Threat } & Severity & 0 & 1 & 0 & 4 & 5 & $49.4 \%$ \\
\hline & Susceptibility & 0 & 0 & 3 & 4 & 3 & \\
\hline \multirow[t]{2}{*}{ Perceived Efficacy } & Self-efficacy & 0 & 0 & 1 & 6 & 3 & $50.6 \%$ \\
\hline & Response Efficacy & 0 & 0 & 1 & 5 & 4 & \\
\hline
\end{tabular}

Table 8 illustrates the level of perceived threat which is $49.4 \%$, being slightly lower compared to perceived efficacy which is $50.6 \%$. This indicates that the respondents perceived the threat as less significant. On the other hand, the high level of perceived efficacy indicated that the respondents strongly believed that they were able to do what was needed to protect themselves from harm as the news headlines given were effective in giving them caution. A closer look at each item in terms of mean is presented in Table 9. 
TABLE 9. Summary of Mean for perceived threat and perceived efficacy

\begin{tabular}{lllcc}
\hline & Item & Mean & Scale Total & Scale Average \\
\hline Perceived Threat & Severity & 4.3 & & \\
& Susceptibility & 4 & 8.3 & $\mathbf{4 . 1 5}$ \\
\hline Perceived Efficacy & Self-efficacy & 4.2 & 8.5 & $\mathbf{4 . 2 5}$ \\
& Response Efficacy & 4.3 & $\mathbf{8 . 5}$ & \\
\hline
\end{tabular}

As illustrated in Table 9 above, although perceived severity is quite high (mean=4.3), perceived susceptibility (mean=4) is the lowest among the variables which made the threat appeared less significant. Although most of them perceived Coronavirus as a severe threat, they felt less vulnerable to it. The high level of perceived efficacy with the scale average of 4.25 influenced by the high means of both self-efficacy (mean=4.2) and response efficacy (mean=4.3) indicated that most of the respondents believed that they were able to avoid being infected and that the news headlines presented were effectual in alerting them. Again, these data demonstrated that the respondents are expected to be engaged in the danger control process. Nevertheless, the perceived susceptibility when using human agency language is much lower (mean=3.8) compared to using virus agency. It shows that, when the agent is assigned to human, the respondents feel less vulnerable to Coronavirus, but when it comes to the virus agency, the respondents feel more threatened. Overall, the fear appeal has a great impact in persuading or stimulating the audience's behaviours.

FEAR AROUSAL AND BEHAVIORAL INTENTION

In order to know whether the linguistic agency assignment affects one's level of fear or behaviour, two additional variables were included in the study to know the degree of fear and behavior of participants when exposed to the stimulus.

TABLE 10. Mean scores for Fear Arousal and Behavioral Intention in both stimuli

\begin{tabular}{lcccc}
\hline & \multicolumn{2}{c}{ Human Agency Language } & \multicolumn{2}{c}{ Virus Agency Language } \\
\hline Variables & Fear Arousal & Behavioral Intention & Fear Arousal & Behavioral Intention \\
Mean & 3.8 & 4.5 & 4.1 & 4.7 \\
\hline
\end{tabular}

From the result displayed in Table 10 above, behavioral intention dominates in both stimulus compared to fear arousal. Both materials stimulated the behavioral intention as most of them 'Agreed' and 'Strongly Agreed' with this statement, "I intend to pay closer attention to what I do to prevent myself from getting Coronavirus". Nonetheless, the level of fear arousal was higher when assigning the virus as the agent (mean=4.1) rather than assigning human as the agent (mean=3.8). The use of virus agency language invoked fear in people. The presence of fear or anxiety in readers can hinder them from engaging in risky behaviours. Consequently, readers would be more inclined to practice preventative measures such as hand washing, social distancing and others. To summarize, ratings of fear arousal were higher when agency was assigned to the virus rather than humans but both stimulated the same behavioral response. Thus, the news headlines induced fear in the audience but at the same time project a high level of awareness to the public to take better precaution of themselves.

All in all, the results obtained were quite different from what have been predicted based on previous studies. Berry et al. found that the media often disseminated Risk-related messages rather than Prevention or Treatment (43) as opposed to the current study where dissemination of Prevention messages was the highest. Furthermore, previous studies have found that assignment of agency to the virus instead of human heightened recipients' susceptibility and severity of the disease (Zhang and McGlone, 2018; Bell et al., 2014). In contrast, the present study found that, perceived severity to the Coronavirus was highest when agency was assigned 
to human rather than to the virus. However, perceived susceptibility was highest when the agency was assigned to the virus. These unexpected findings might be explained by the characteristics of the virus. Coronavirus is a novel disease where treatments are yet to be found and the risk of transmission is high. The transmission is most likely to occur through close contact and respiratory droplets. Since the risk of transmission is high, thus, news agencies tend to disseminate preventive measures of COVID-19. Moreover, the virus is mostly transmitted from human to human which explains why perceived susceptibility is high when the agency is assigned to humans. Although the questionnaire was distributed at a time where MCO restrictions were quite lenient and Coronavirus infected cases have gradually decreased, yet, perceived severity as well as fear arousal were much higher when the agency was assigned to the virus than to humans. Lastly, the respondents' age or the nature of their occupations may affect their response towards perceived threat and perceived efficacy. As mentioned before, all participants recognised Coronavirus as a severe threat but some of them felt that they were not susceptible to getting infected by it. It could be due to the age factor (the risk of getting infected), as well as their employment status (the risk of occupational exposure), since the participants who contributed to the low mean of perceived susceptibility were among students who underwent remote learning, aged 19 and a housewife, aged 53.

\section{IMPLICATIONS}

The framework of this study, which is Linguistic Agency Assignment, is commonly used to analyse articles related to health educational materials, such as health magazines and flyers. To the researchers' knowledge, this study is unique and novel as it uses the framework to analyse news headlines on a deadly disease within the Malaysian context. Generally, this study could benefit journalists, health professionals as well as students in the communication field to develop effective health messages. The findings of this study suggest that linguistic agency assignment can significantly enhance the persuasive power of not only health educational materials, but also news reports. It can be inferred that non-health practitioners or communicators can use this linguistic feature in designing health-related messages to be used on different platforms to achieve their communicative goals. Practically, this research is expected to provide other researchers, especially local researchers in Malaysia, insights for them to do further research in the field of linguistics and communication, specifically in media discourse studies. This study also provides some insights into the language use by one of the Malaysian news agencies, where the journalists tend to present humans as the agent in disseminating risk-related messages. Yet, the level of fear arousal and behavioral intention among participants was heightened when the virus was presented as the agent. An implication of this is the possibility that the overuse of virus agency assignment in news reports may contribute to an uncontrolled surrounding. This matter should not be taken lightly as news media plays an important role in delivering information to the public and has the ability to manipulate or persuade others to behave in certain ways (Alo \& Orimagunje, 2013).

\section{CONCLUSION}

The current study examined the dissemination of news headlines on COVID-19 in terms of health-related messages i.e. Prevention, Risk or Treatment and applied linguistic agency assignment theory to find out whether the news headlines induced anxiety or awareness to the public. The findings revealed that The Star Online usually disseminated news discussing more on Prevention of COVID-19 compared to Risk and Treatment. About 495 news headlines 
included contents on 'prevention' which primarily discussed preventative measures to curb the virus such as lockdown, social distancing and others. It could be deduced that the main aim of the news in March 2020 was to disseminate massive information on several measures to reduce or slow down the spread of the virus infection. It was also revealed that journalists tend to adopt human linguistic agency assignment when writing risk-related news headlines with 21 occurrences, followed by virus agency assignment with 15 occurrences. This could be due to the fact that the writers wanted the readers to realise that they could become the potential cause for an event to happen which is virus transmission during the pandemic.

The study also found that there was no significant difference between the effects of using human agency language versus virus agency language in which both created awareness to the public to engage in the danger control process. Most of the participants perceived Coronavirus as a severe threat and believed that the news headlines presented were giving them caution. In terms of fear arousal, the participants' level of fear was usually higher when 'virus' was assigned as agency compared to 'human' as agency. However, the presence of fear in people helped them to behave in a certain way i.e., protecting themselves from harm. Therefore, fear appeals used by linguistic agency assignment were effective in stimulating respondents' behaviours which indirectly created awareness in them and propelled them to take the necessary preventive measures.

However, this study has several limitations. First, the sample size was small. Furthermore, the contexts presented in stimulus materials were quite limited and thus, only a small number of questions could be asked. In spite of the limitations, the study led to a better understanding of the use of linguistic agency assignment and Extended Parallel Process Model (EPPM) in designing different materials effectively. It is suggested for future research to examine the effects of respondents' age or the nature of their occupations on perceived threat and perceived efficacy. Also, this study could be replicated during different stages of the pandemic to identify whether there is shift in focus in the news headlines i.e., from prevention to risk or treatment and how this affects the readers.

\section{REFERENCES}

Alo, M. \& Orimogunje, A. (2013). Discourse strategies and ideology in selected radio lead news of Osun State Broadcasting Corporation, Nigeria. 3L: Language, Linguistics, Literature. 19(2), 111-123.

Bada, M., Sasse, A. M., \& Nurse, J. R. (2019). Cyber security awareness campaigns: Why do they fail to change behaviour?. International Conference on Cyber Security for Sustainable Society, 2015.

Bell, R. A., McGlone, M. S., \& Dragojevic, M. (2014). Bacteria as bullies: Effects of linguistic agency assignment in health message. Journal of Health Communication, 19(3), 340-358.

Berry, T. R., Wharf-Higgins, J., \& Naylor, P. J. (2007). SARS wars: An examination of the quantity and construction of health information in the news media. Health communication, 21(1), 35-44.

Braun, V., Clarke, V. (2006). Using thematic analysis in Psychology. Qualitative Research in Psychology, 3, 77101.

Chen, M., McGlone, M. S., \& Bell, R. A. (2015). Persuasive effects of linguistic agency assignments and point of view in narrative health messages about colon cancer. Journal of health communication, 20(8), 977988.

China using traditional Chinese medicine on coronavirus patients. (2020, February 15). The Straits Times. https://www.straitstimes.com/asia/east-asia/china-using-traditional-chinese-medicine-on-coronaviruspatients

Cillizza, C. (2014, March 19). Americans read headlines. And not much else. The Washington Post. https://www.washingtonpost.com/news/the-fix/wp/2014/03/19/americans-read-headlines-and-not-much$\underline{\text { else/ }}$

Conboy, M. (2007). The language of the news. Routledge.

Faheem Aslam., Tahir Mumtaz Awan., Jabir Hussain Syed., Aisha Kashif., \& Mahwish Parveen. (2020). Sentiments and emotions evoked by news headlines of coronavirus disease (COVID-19) outbreak. Humanities and Social Sciences Communications, 7(1), 1-9. 
Indonesia president Jokowi claims herbs can fight Covid-19. (2020, March 13). The Star Online. https://www.thestar.com.my/news/regional/2020/03/13/indonesia-president-jokowi-claims-herbs-canfight-covid-19

Kertanegara, M. R. (2018). Clickbait headline and its threat. In The National Resilience. CoverAge: Journal of Strategic Communication, 8(2), 57-62.

Malaysia's 2019 Media Consumption Report. (2019, September 6). https://vase.ai/resources/malaysias-mediaconsumption-2019/

McGlone, M. S., Bell, R. A., Zaitchik, S. T., \& McGlynn III, J. (2013). Don't let the flu catch you: Agency assignment in printed educational materials about the $\mathrm{H} 1 \mathrm{~N} 1$ influenza virus. Journal of Health Communication, 18(6), 740-756.

Pokharel, S. (2015). An examination of moral panic in the British press coverage of the 2014 Ebola outbreak in West Africa [Unpublished doctoral dissertation]. Cardiff University.

Reventlow, S., Hvas, A.C. \& Tulinius, C. (2001). "In really great danger..." The concept of risk in general practice. Scandinavian Journal of Primary Care, 19(2), 71-5.

Reuters report: Astro Awani and The Star among most trusted of Malaysian news organisations. (2018, June 2018). The Star Online. https://www.thestar.com.my/news/nation/2018/06/27/reuters-report-astro-awaniand-the-star-among-most-trusted-of-malaysian-news-organisations

Sandman, P. M. (1994). Mass media and environmental risk: Seven principles. Risk, 5, 251-260.

Seale, C. F. (2004). Media \& health. Sage

Stem cell therapy used to treat severe cases. (2020, March 6). The Star Online. https://www.thestar.com.my/news/regional/2020/03/06/stem-cell-therapy-used-to-treat-severe-cases

Steuter, E., \& Wills, D. (2009). At war with metaphor: Media, propaganda, and racism in the war on terror. Lexington books.

Maas., P.H. (2016). What is meant by prevention? [Unpublished Thesis]. Eindhoven University of Technology. Netherlands.

Thompson, T. L., Parrott, R., \& Nussbaum, J. F. (Eds.). (2011). The Routledge handbook of health communication. Routledge.

Venes, D. (2017). Prevention. Taber's Cyclopedic Medical Dictionary. F.A Davis Company.

Venes, D. (2017). Risk. Taber's Cyclopedic Medical Dictionary. F.A Davis Company.

Venes, D. (2017). Treatment. Taber's Cyclopedic Medical Dictionary. F.A Davis Company.

Vigo, D., Patten, S., Pajer, K., Krausz, M., Taylor, S., Rush, Raviola, G., Saxena, S., Thornicroft, G. \& Yatham, L. N. (2020). Mental Health of Communities during the COVID-19 Pandemic. The Canadian Journal of Psychiatry, 65, 1-7.

Witte, K. (1992). Putting the fear back into fear appeals: The extended parallel process model. Communication Monographs, 59, 225-249.

Witte, K., Berkowitz, J. M., Lillie, J. M., Cameron, K. A., Lapinski, M. K., \& Liu, W. Y. (1998). Radon awareness and reduction campaigns for African Americans: A theoretically based evaluation. Health Education \& Behavior, 25(3), 284-303.

Zhang, Z., \& McGlone, M. S. (2018). Language matters: Effects of linguistic agency assignment on HPV prevention advocacy in Chinese public health education materials. Chinese Journal of Communication, 12(2), 166-184.

Zonouzy, V. T., Niknami, S., Ghofranipour, F., \& Montazeri, A. (2019). An educational intervention based on the extended parallel process model to improve attitude, behavioral intention, and early breast cancer diagnosis: A randomized trial. International journal of women's health, 11, 1-10. 